Kalokairinou, L., Borry, P., Howard, H.C. (2019). Attitudes and experiences of European clinical geneticists towards direct-to-consumer genetic testing: a qualitative interview study. NEW GENETICS AND SOCIETY, 38 (4), 410-429. doi:

$\underline{10.1080 / 14636778.2019 .1677149}$

\title{
Attitudes and Experiences of European Clinical Geneticists towards Direct-to-Consumer Genetic Testing: A Qualitative Interview Study
}

\author{
Louiza Kalokairinoua*, Pascal Borry ${ }^{\mathrm{a}}$ and Heidi C. Howard ${ }^{\mathrm{b}}$ \\ aDepartment of Public Health and Primary Care, Centre for Biomedical Ethics and

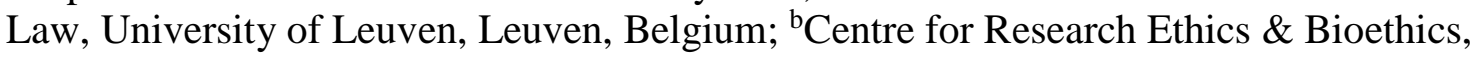 \\ Uppsala University, Uppsala, SwedenAbstract
}

Direct-to-consumer (DTC) genetic tests (GT) enable consumers to access a wide range of GT, without involving a healthcare professional, promoting an increasing disassociation of genetics from the clinical context. This study explores, through semi-structured interviews, the experiences and attitudes of European clinical geneticists towards DTCGT. Our results indicate that the participants have limited experience of consultations with patients regarding such tests. In the majority of cases, the participants stated that consumers purchased tests out of curiosity and sought a general interpretation of test results by a healthcare professional. Most respondents were skeptical of the quality of these tests, especially regarding their clinical utility. The participants supported the importance of medical supervision and genetic counseling in this context. Finally, most respondents considered it their duty to accept consultations concerning DTCGT results. However, due to concerns over limited time and potential downstream costs, some participants supported that a prioritization system based on guidelines would be necessary.

\section{Keywords}

Direct-to-consumer, genetic testing, medical supervision, genetic counseling 
Kalokairinou, L., Borry, P., Howard, H.C. (2019). Attitudes and experiences of European clinical geneticists towards direct-to-consumer genetic testing: a qualitative interview study. NEW GENETICS AND SOCIETY, 38 (4), 410-429. doi:

$\underline{10.1080 / 14636778.2019 .1677149}$

\section{Introduction}

Direct-to-consumer (DTC) genetic tests (GT) have been available online for over a decade now, offering consumers the chance to access a wide range of GT, often without involving a healthcare professional (Hogarth, Javitt, and Melzer 2008).

In this regard, DTC genetic testing challenges the traditional provision model, according to which GT are being offered through the healthcare system, with genetic counsellors and clinical geneticists being considered the gatekeepers of this process. Contrary to this, in the DTC model, the consumer/patient plays a central role in ordering the test, receiving and often interpreting the test result, as well as implementing lifestyle changes, as in many cases seeking advice by a healthcare professional is at the discretion of consumers (Allyse et al., 2018). In this context, DTC genetic testing promotes an increasing disassociation of genetic testing from the clinic and blurs the lines between medical devices and consumer goods (Kalokairinou et al., 2017).

This model of provision has been seen by some as a way of "democratizing" genomics, by enabling direct access of consumers to their genetic data, and as a way to promote autonomy and genetic literacy of the public (Lee 2013). Nevertheless, these tests have also received strong criticism. Concerns voiced include, among others, the uncertain clinical validity and utility of such tests and potential negative consequences on consumers stemming from the lack of guidance by a healthcare professional (Tamir 2010). 
Kalokairinou, L., Borry, P., Howard, H.C. (2019). Attitudes and experiences of European clinical geneticists towards direct-to-consumer genetic testing: a qualitative interview study. NEW GENETICS AND SOCIETY, 38 (4), 410-429. doi:

$\underline{10.1080 / 14636778.2019 .1677149}$

Over the past years, the phenomenon of DTC genetic testing has been the subject of extensive debates in the literature and has been explored from many different angles. While several empirical studies have been conducted on the attitudes of consumers (Baptista et al., 2016; Bloss et al., 2013; Bollinger et al., 2013; Goldsmith et al., 2012; Gollust et al., 2017; Ostergren et al., 2015; Vayena et al., 2012) and of the general public (Cherkas et al., 2010; Kolor et al., 2012; Mcguire et al., 2009) towards this type of testing, there is only a limited number of studies that has explored the point of view of healthcare professionals (Carroll et al., 2016; Goldsmith et al., 2013; Hock et al., 2011; Howard and Borry, 2013).

In this regard, an explorative qualitative interview study was undertaken aiming to explore the experiences and attitudes of European clinical geneticists towards DTC genetic testing and its regulation. While there are some studies exploring the attitudes of healthcare professionals from individual European countries (Finlay 2017; Urban and Schweda 2018), to our knowledge, this is the first qualitative interview study with European healthcare professionals regarding DTC genetic testing which does not focus on single countries, but rather includes clinicians from across Europe. This study is a follow up of a survey study exploring the attitudes of European clinical geneticists towards DTC GT (reference has been removed for the purposes of the double blind peer review). Because of the rich content of the interviews, the results are presented in two separate articles: the current article focusing on the experience of the participants with patients having undergone DTC GT and their attitudes towards these tests, and an article focusing on the attitudes of clinical geneticists towards the regulation of DTC GT in Europe (reference has been removed for the purposes of the double blind peer review). Both articles are based on the same methodology. 
Kalokairinou, L., Borry, P., Howard, H.C. (2019). Attitudes and experiences of European clinical geneticists towards direct-to-consumer genetic testing: a qualitative interview study. NEW GENETICS AND SOCIETY, 38 (4), 410-429. doi:

$\underline{10.1080 / 14636778.2019 .1677149}$

Herein, we report on a subset of four themes relating to DTC genetic testing that were raised in these interviews: i) the frequency of consultations with patients having undergone DTC genetic testing ii) the perceptions of clinical geneticists on the quality of the tests iii) the importance of medical supervision and genetic counseling in the genetic testing process and iv) what do they consider to be their responsibilities with regard to this emerging model of providing GT (Table I).

\section{Materials and Methods}

\section{Rationale of the study}

This is an interdisciplinary empirical bioethics and public health study that aims to complement the existing literature debate on DTC GT and the relevant normative assumptions with empirical insight. In this regard, this study aims to explore the experiences of clinical geneticists, a group of stakeholders that is traditionally seen as the gatekeepers of the genetic testing process and whose role is often diminished in the context of consumer genomics.

While a number empirical studies exploring the attitudes of healthcare professionals on DTC genetic testing have already been performed, the majority focuses on healthcare professionals based in the USA, leaving the European landscape largely unexplored. While healthcare systems and the specifics of providing genetic testing may differ across Europe, overall it can be argued that, despite their differences, the provision of genetic tests in most countries has been closely linked to the traditional healthcare system, and that, in principle, the commercialization of healthcare services tends to be less pronounced compared to the USA. In this regard, considering also that there is a strong network of geneticists in Europe, it can be 
Kalokairinou, L., Borry, P., Howard, H.C. (2019). Attitudes and experiences of European clinical geneticists towards direct-to-consumer genetic testing: a qualitative interview study. NEW GENETICS AND SOCIETY, 38 (4), 410-429. doi:

$\underline{10.1080 / 14636778.2019 .1677149}$

argued that there are uniting features among individual European countries that form a European perspective, which is worth exploring further.

In this regard, the added value of this study resides, first of all, in its aim to provide qualitative empirical insight on the attitudes of a largely underrepresented in the literature stakeholder group, namely that of clinical geneticists across Europe. Secondly, as opposed to many existing studies, this work aims to explore actual experiences of participants with patients having undergone DTC GT and their attitudes towards these services, which are informed by such experiences.

\section{Recruitment}

This research builds up on a survey study focusing on the awareness, experiences and attitudes of clinical geneticists regarding DTC GT (reference has been removed for the purposes of the double blind peer review). After performing the survey study, we were able to identify participants having indicated that they have had experiences with patients having undergone DTC genetic testing and invited them to participate in the current study. Identification of additional interviewees occurred during the study by searching websites of healthcare institutions in Europe and using the snowballing approach.

The inclusion criteria for this study were for participants 1) to be clinical geneticists, 2) to be professionally active in a healthcare institution based in a country where the newly adopted EU Regulation on in vitro diagnostic medical devices (relevant for the oversight of genetic testing) will apply (i.e. EU Member States, European Free Trade Association countries and Turkey) and 3) to have been approached by at least one patient who had purchased or was considering purchasing a DTC genetic test. 
Kalokairinou, L., Borry, P., Howard, H.C. (2019). Attitudes and experiences of European clinical geneticists towards direct-to-consumer genetic testing: a qualitative interview study. NEW GENETICS AND SOCIETY, 38 (4), 410-429. doi:

$\underline{10.1080 / 14636778.2019 .1677149}$

\section{Data Collection and Analysis}

The interview guide was developed after an extensive review of the relevant literature (Kalokairinou et al. 2014; Sleurs et al. 2015; Borry, Cornel, and Howard 2010; Heidi Carmen Howard and Borry 2012). The first part of the interviews focused on questions related to the experiences of the clinical geneticists with patients having undergone DTC genetic testing and their views and beliefs regarding this type of testing. In the second part, which is reported separately, the participants were asked questions regarding their attitude towards the regulation of DTC genetic testing. The semi-structured format of the interview guide allowed the interviewee to speak in his/her own words and elaborate on their personal opinions (Berg 2007). The terms DTC genetic testing and patient were not predefined in the context of this study, in order to allow participants to give their interpretation of the terms.

The interviews took place in person, via telephone or Skype between February 2015 and May 2016. Upon obtaining informed consent of the participants, all interviews were audiotaped. The audio files were de-identified and transcribed verbatim by the research team. The data analysis was based on an iterative process, combining deductive and inductive methods in order to identify common themes stemming from the interviews (Merriam 2009). The entire data set was categorized on the basis of codes attributed to these themes as described by Braun and Clarke (2006) under the section "Doing thematic analysis: a step by step guide" of their article "Using thematic analysis in psychology". This study is data-driven and, therefore, the themes developed stem directly from the data, and are not based on a priory conceived theory (Braun and Clarke 2006). In the first part of the data analysis, a subset of the interviews was coded 
Kalokairinou, L., Borry, P., Howard, H.C. (2019). Attitudes and experiences of European clinical geneticists towards direct-to-consumer genetic testing: a qualitative interview study. NEW GENETICS AND SOCIETY, 38 (4), 410-429. doi:

$\underline{10.1080 / 14636778.2019 .1677149}$

and discussed within a team for validation. This study obtained approval by the Social and Societal Ethics Committee of the University of Leuven in January 2015.

\section{Results}

Interviews were performed with fifteen clinical geneticists from ten European countries. More specifically, the clinicians interviewed were professionally active in Belgium, the Czech Republic, Finland, France, Ireland, the Netherlands, Slovenia, Sweden, Turkey and the UK. The participants described their experiences with patients who had approached them in order to discuss issues related to DTC GT. Most clinical geneticists held consultations with patients who had already undergone DTC genetic testing. In one case, the participant reported delivering pre-test genetic counseling, while two of the participants reported to only have second-hand experience through discussing with their colleagues cases that took place in their clinic.

Examples of DTC GT that interviewees reported to have encountered in their practice were Personal Genome Scans, carrier tests, nutrigenomics tests, pharmacogenomic tests, BRCA tests and whole exome sequencing. Most clinical geneticists reported experiences with companies that advertise and sell GT without involving healthcare professionals. However, a few participants interpreted DTC genetic testing in a broad way that encompasses commercial laboratories which, although advertise their products DTC, sell GT through physicians.

With one notable exception, most participants reported that their experience with such patients has been rather limited in their years of practice and they offered explanations as to why this is the case. Participants elaborated on the motivations of patients to undergo DTC genetic 
Kalokairinou, L., Borry, P., Howard, H.C. (2019). Attitudes and experiences of European clinical geneticists towards direct-to-consumer genetic testing: a qualitative interview study. NEW GENETICS AND SOCIETY, 38 (4), 410-429. doi:

$\underline{10.1080 / 14636778.2019 .1677149}$

testing and the reasons that motivated them to visit a healthcare professional after undergoing such testing. Furthermore, the clinical geneticists shared their opinion regarding the tests undertaken by their patients. In this regard, the participants elaborated on how confident they felt interpreting this type of tests, what was their opinion on the test reports and the quality of the tests. Finally, the respondents also weighed in on how important it is to have medical supervision and genetic counseling in the context of DTC GT and explained what they think is their responsibility as physicians towards DTC genetic testing consumers asking for their help. 
Kalokairinou, L., Borry, P., Howard, H.C. (2019). Attitudes and experiences of European clinical geneticists towards direct-to-consumer genetic testing: a qualitative interview study. NEW GENETICS AND SOCIETY, 38 (4), 410-429. doi:

$\underline{10.1080 / 14636778.2019 .1677149}$

\section{Limited Experience of Clinical Geneticists and Conducive Reasons}

Most clinical geneticists participating in our study have reported that it has been rather unusual in their years of practice to hold consultations with patients who have undergone DTC genetic testing. A notable exception to this is the instance of a clinical geneticist working in a public hospital that cooperated with a commercial company. In this case, the hospital promoted pharmacogenomics, susceptibility and carrier DTC GT to patients. This resulted in hundreds of patients having consultations with clinical geneticists within the hospital.

For the rest of participants, holding such consultations was reported as something rather rare. Several respondents considered this to be a reflection of low uptake of such tests in the population in general. In this regard, one clinical geneticist stated:

Firstly, I have no means to precisely estimate the uptake of the tests but based on the information that we got from other colleagues, doctors, let's say, it shouldn't be too big because otherwise more patients or DTC testing people would look for medical consultations further on. So I believe that there is not a large uptake, there is some, definitely, we know that, but on the other hand, the companies, for sure, don't have clinical geneticists to provide genetic counseling with those tests.

(Interview 11) 
Kalokairinou, L., Borry, P., Howard, H.C. (2019). Attitudes and experiences of European clinical geneticists towards direct-to-consumer genetic testing: a qualitative interview study. NEW GENETICS AND SOCIETY, 38 (4), 410-429. doi:

$\underline{10.1080 / 14636778.2019 .1677149}$

Furthermore, many clinical geneticists underlined that their national healthcare system is very efficient and offers access to a broad range of GT. As a result, people in need of genetic testing do not have to resort to private companies in order to access it. In this regard, one participant explained:

It is exceptionally unusual for patients to be referred to genetic services to discuss the results of testing that came privately because access to genetic services and genetic testing in [our national healthcare system] is widely available to everybody so there is no reason why people should need to seek to pay for those tests privately.

(Interview 2)

It has also been pinpointed that DTC GT consumers may not feel the need to have a consultation with a clinical geneticist, as they usually take the tests out of curiosity and not because they have specific health concerns. As one interviewee speculated:

Most of the people who are suffering from something or are concerned about a genetic disease in the family they will go to the doctor, to a GP, and then this person will refer the patient to the genetic center, or the patient will call directly to the genetic center if there is a medical problem. I think that the people who are sending their saliva or blood to a company that provides DTC testing are the ones who are a bit curious about their genetic predisposition. It's more questions about 
Kalokairinou, L., Borry, P., Howard, H.C. (2019). Attitudes and experiences of European clinical geneticists towards direct-to-consumer genetic testing: a qualitative interview study. NEW GENETICS AND SOCIETY, 38 (4), 410-429. doi:

$\underline{10.1080 / 14636778.2019 .1677149}$

predisposition to cancer, to dementia, to common problems and most of them are not sick I believe.

(Interview 10)

Moreover, a respondent claimed that it is likely that some consumers may resort to DTC GT because of potential luck of trust in the public healthcare system. According to the same interviewee, participants who have not trusted the healthcare system in the first place to take a genetic test are very unlikely to request a consultation regarding their test results within this system:

Well, my idea, but this is not something that I'm sure of, is that if people want to do testing at DTC companies it might be because they don't rely on the normal healthcare or that they don't feel that they have been listened to from the normal healthcare, then they chose to have another sort of options or searching for a diagnosis or searching for health. Sometimes I see it as a failure for the normal healthcare [...] Because [...] if we do have this national healthcare which everybody doesn't have to pay so much and just feel confident in getting the help you need, then when people feel that they want to move further outside that? Then I feel we have somehow failed in giving them the confidence that we can help them.

(Interview 9) 
Kalokairinou, L., Borry, P., Howard, H.C. (2019). Attitudes and experiences of European clinical geneticists towards direct-to-consumer genetic testing: a qualitative interview study. NEW GENETICS AND SOCIETY, 38 (4), 410-429. doi:

$\underline{10.1080 / 14636778.2019 .1677149}$

\section{Motivations of Patients to Take the Test and/or Visit a Clinical Geneticist}

Most clinical geneticists reported that their patients had undertaken DTC GT out of curiosity, namely because they wanted to learn more about what their genome could reveal about themselves. These patients did not have any specific health-related indication or concern for undergoing the test. In this regard, it was also mentioned that DTC GT has become a trend and consumers tend to be influenced by its advertising.

In two cases, the interviewees have been consulted by journalists who had been through this type of testing as part of their research. In several other cases, however, according to interviewees, the patients had resorted to DTC genetic testing companies for health reasons, namely because they were worried about their genetic risk of developing specific diseases. Some of these concerns were based on the family history of the patients and in some of these cases, the patient had purchased the test following a doctor's recommendation. In other instances, however, the patients were reported to have purchased the tests on their own initiative, with personal concerns about potentially developing a disease being the sole foundation of this decision.

Regarding the patients who purchased DTC GT because they were worried or wanted to have more information about their health, the clinical geneticists speculated that they resorted to private companies rather than the healthcare system either because they did not qualify for such testing in the public healthcare system, or for reasons of convenience and avoiding the waiting period in hospitals, or potentially due to the lack of trust to the public healthcare system. 
Kalokairinou, L., Borry, P., Howard, H.C. (2019). Attitudes and experiences of European clinical geneticists towards direct-to-consumer genetic testing: a qualitative interview study. NEW GENETICS AND SOCIETY, 38 (4), 410-429. doi:

$\underline{10.1080 / 14636778.2019 .1677149}$

With one exception, all patients asked for a consultation with a clinical geneticist upon obtaining the test results. In most cases, the clinical geneticists stated that the patients requested a general interpretation of the test results, while in fewer cases, patients asked information regarding specific mutations identified by the tests. In one notable occasion, the patient had undertaken a genetic test out of curiosity, but the results turned out to be medically relevant, as they indicated that he was predisposed to a very rare form of cancer.

I think it started like an adventure. It started like something of curiosity and then, when he got back the results, I think he was a bit shocked. Because he was not suspecting this, that he was carrying a cancer gene mutation. And so he didn't know what to do with it. He didn't know if it was relevant, so he wanted to see someone, he wanted to see an expert to explain him what to do about it.

(Interview 10) 
Kalokairinou, L., Borry, P., Howard, H.C. (2019). Attitudes and experiences of European clinical geneticists towards direct-to-consumer genetic testing: a qualitative interview study. NEW GENETICS AND SOCIETY, 38 (4), 410-429. doi:

$\underline{10.1080 / 14636778.2019 .1677149}$

\section{Ability of Participants to Interpret the Tests and their Views on Quality of the Tests and}

\section{Test Reports}

In general, the respondents of the study felt adequately prepared to interpret the test results provided by companies. Many participants drew a distinction between, on the one hand clinical geneticists and genetic counselors, who were generally considered well-placed to interpret such tests, and on the other, physicians without specialization in genetics (e.g. general practitioners and pediatricians) who the interviewees tend to consider as less wellinformed and less prepared to interpret such test results. In one case, a participant mentioned that some preparation was needed in view of the consultations, as susceptibility tests is not something frequently encountered in their practice. However, following this preparation, the interpretation was not challenging.

Some respondents found the reports provided by the companies to be of good quality and the results technically sound and delivered in a timely manner. However, the speed in the delivery of results was often attributed to the lack of genetic counseling in this process. Nevertheless, confirmation tests were deemed necessary in cases of test results providing medically relevant information. In particular, some of the participants expressed doubts regarding whether they can trust test results provided by the companies.

Although all interviewees considered the clinical validity of DTC GT to vary depending the type of the test, the vast majority expressed concerns regarding the clinical utility of DTC GT for multifactorial disorders. In this context, the dynamic nature of genetic information over 
Kalokairinou, L., Borry, P., Howard, H.C. (2019). Attitudes and experiences of European clinical geneticists towards direct-to-consumer genetic testing: a qualitative interview study. NEW GENETICS AND SOCIETY, 38 (4), 410-429. doi:

$\underline{10.1080 / 14636778.2019 .1677149}$

time it was mentioned as well as that the commercialization of such tests is, at this moment, rather premature:

I think that they are at very early stages. Anything preliminary today might have some very good background in five years from now, so we don't know. I don't think we should throw them away completely, but I wouldn't recommend them for another five years.

(Interview 13)

The clinical utility of tests for monogenic disorders was also questioned by some, on the basis that in some cases, there is only one small part of the gene being screened.

And I've noticed that if you go for BRCA 1 or 2 testing they are only testing three SNPs out of hundred different mutations. And these are only the Jewish mutations. So what good does that make, you know, to test someone from Finland or Russia for these Ashkenazi Jewish mutations? And then you get a result that you are negative. You have no increased risk. This is not very good in my mind.

(Interview 15)

Furthermore, in many cases the participants mentioned that they felt that the tests were irrelevant for their patients and that companies ignored the family history of consumers and the context of the countries where they sell the tests. 
Kalokairinou, L., Borry, P., Howard, H.C. (2019). Attitudes and experiences of European clinical geneticists towards direct-to-consumer genetic testing: a qualitative interview study. NEW GENETICS AND SOCIETY, 38 (4), 410-429. doi:

$\underline{10.1080 / 14636778.2019 .1677149}$

The American company gave them the same price for each test, for example they were three types of tests, one of them was the pharmacogenetics test, the other one was the disease, common disease test, the third one was the carrier test. So what they did commercially is that they offered all three of them to everyone. So I had postmenopausal women being counseled with carrier testing and what happened is that there was too much knowledge in the report and most of it was not relevant to the patient at that point.

(Interview 13)

Nevertheless, it was also mentioned that such tests may have a subjective clinical utility (also referred to as "personal utility"). Hence, utility in a broad sense may depend on the circumstances of any one patient.

Well, it depends, I mean this person took it out of curiosity and then by chance something was found that was actually important for his health.

So yes it was clinically useful, but this doesn't mean that everyone should have done this test.

(Interview 10) 
Kalokairinou, L., Borry, P., Howard, H.C. (2019). Attitudes and experiences of European clinical geneticists towards direct-to-consumer genetic testing: a qualitative interview study. NEW GENETICS AND SOCIETY, 38 (4), 410-429. doi:

$\underline{10.1080 / 14636778.2019 .1677149}$

In addition, despite the lack of medical relevance and, therefore, clinical utility, several respondents found recreational tests, such as ancestry and fitness tests, to be entertaining and interesting.

Well, they also have this part where you can look at your ancestry and I don't think that this is medically very important, but it's recreational genetics and, well, I don't mind recreation. So if people are interested in their ancestry of course this is a way to get some data. Sometimes it can be interesting but it's very rarely relevant for medical situations. (Interview 5)

\section{Importance of Medical Supervision and Genetic Counseling}

The vast majority of respondents agreed that it is necessary for a healthcare professional to be involved in the process of health-related genetic testing, in order to provide an accurate assessment of test results. Furthermore, some of the interviewees supported that, genetic counseling could also be offered by companies. Nevertheless, this was a minority opinion, as most participants expressed concerns regarding the impartiality of healthcare professionals employed by companies and the potential conflict of interest emerging in this context.

But [the companies and healthcare professionals working for them] will also have this commercial goal. So then I will be a little afraid about okay what is their goal? Is it really healthcare? Or is it really making 
Kalokairinou, L., Borry, P., Howard, H.C. (2019). Attitudes and experiences of European clinical geneticists towards direct-to-consumer genetic testing: a qualitative interview study. NEW GENETICS AND SOCIETY, 38 (4), 410-429. doi:

$\underline{10.1080 / 14636778.2019 .1677149}$

money? So the pre- and post-test counseling will that be very objective

or will that be directed and inspired by economic drives?

(Interview 4)

Although some respondents considered post-test counseling more important than pre-test counseling, it was frequently reported that the lack of adequate pre-test information in the cases of their patients had led some patients to undertake inappropriate tests and/or to be underwhelmed by test results. More specifically, it has been reported that in some cases the limitations of the test were not clear to the patients from the beginning and that led to them to be disappointed when they eventually received the test results.

Because the main feeling of the patient after the genetic counseling session was actually disappointment because they were expecting to have their whole DNA mapped in front of them and it was not the case and some of the things they heard were just volatile and blurry. Some of the things they heard didn't mean anything and mostly they were just recommended to exercise and not smoke and live a healthy life.

(Interview 13)

\section{Responsibilities of the Healthcare System and of Healthcare Professionals}

Even though participants almost unanimously considered the offer of GT in their public healthcare system to be adequate, some emphasized that authorities should always ensure access to health-related genetic testing to people in need of it. More specifically, some 
Kalokairinou, L., Borry, P., Howard, H.C. (2019). Attitudes and experiences of European clinical geneticists towards direct-to-consumer genetic testing: a qualitative interview study. NEW GENETICS AND SOCIETY, 38 (4), 410-429. doi:

$\underline{10.1080 / 14636778.2019 .1677149}$

participants felt uncomfortable with the idea that people may have to pay to access relevant health-related information. In this regard, it was supported that if a genetic test is of proven clinical utility, then it is the responsibility of the authorities to make it available to the population via the healthcare system.

But, in the end, I feel, I don't like the idea that people need to take money from their own pocket to get such information. If such information would have been important or useful for individuals then it should be offered via the public healthcare and not via private companies.

(Interview 9)

When it comes to the roles and responsibilities of clinical geneticists towards patients seeking consultation on DTC GT results, the vast majority of interviewees felt strongly that it is their duty to inform and guide patients and protect them from tests that they consider to be invalid. In this regard, some participants stressed that anyone who seeks a consultation with a physician because they are worried about their health (regardless of whether this concern is well-founded or not), should be considered a patient. Many interviewees highlighted that interpretation of test results by healthcare professionals and further guidance and support in this context is important in order for patients to be able to take beneficial healthcare decisions and to introduce lifestyle changes. That was especially the case with some respondents who felt that their patients have been misled and misinformed and that it was important for them to interpret the results and explain their limitations. 
Kalokairinou, L., Borry, P., Howard, H.C. (2019). Attitudes and experiences of European clinical geneticists towards direct-to-consumer genetic testing: a qualitative interview study. NEW GENETICS AND SOCIETY, 38 (4), 410-429. doi:

$\underline{10.1080 / 14636778.2019 .1677149}$

But you cannot blame the consumer if they take a test and you realize that they were completely mislead. This is why we try to help them out even at our own expense of time and money, you know, we counsel these cases because we know that they were misled.

(Interview 12)

However, it was also mentioned that constraints in time and resources made it practically difficult for geneticists to hold such consultations.

Well, the role of the physician has to be to guide the patient if they are asked about it. If a patient does come along with significant worries about the results they've got, it becomes very difficult not to address those worries. And so I think it's a reluctant acceptance because we've got enough to do doing the things that really matter.

(Interview 6)

Taking into account such pragmatic constrains, many respondents mentioned that prioritizing cases is one of the main responsibilities of clinical geneticists in this context. In this regard, it was mentioned that given the limited number of geneticists in most European countries, cases of patients that have undergone genetic testing without a medical indication are usually not prioritized. 
Kalokairinou, L., Borry, P., Howard, H.C. (2019). Attitudes and experiences of European clinical geneticists towards direct-to-consumer genetic testing: a qualitative interview study. NEW GENETICS AND SOCIETY, 38 (4), 410-429. doi:

$\underline{10.1080 / 14636778.2019 .1677149}$

[...] and the thing is we don't have so much time allocated for them

[DTC GT consumers] because geneticists are overstretched here as you

know. Everywhere in Europe there are very few professionals who can

do the interpretation and we need to prioritize and also this consultation

is not covered by the health insurance, because they don't have a clear

medical indication for counseling, right? [...] It is not reimbursed and

we do it as a public outreach. And, as you can imagine, we just do it

when we have time for it.

(Interview 12)

Some clinicians interviewed suggested that geneticists should decide, based on guidelines, if they should hold consultations with patients regarding DTC genetic testing results. Many respondents mentioned that the criterion for prioritizing such cases would be the severity of the mutation identified, as verification of GT that were not indicated and have limited clinical utility would be a waste of scarce resources and time.

[I wouldn't have a consultation with such consumers] Not unless it's on a very small list of completely treatable actionable genetics... Because we are very concerned that we will be sucked into doing very expensive verification tests, where such tests were not indicated and where we wouldn't be in a resource place to offer the test in the first place. So I mean, we are particularly thinking about carrier status for rare metabolic disorders where it's not relevant if the risk is low because the chances of the partner being carrier are low. 
Kalokairinou, L., Borry, P., Howard, H.C. (2019). Attitudes and experiences of European clinical geneticists towards direct-to-consumer genetic testing: a qualitative interview study. NEW GENETICS AND SOCIETY, 38 (4), 410-429. doi:

$\underline{10.1080 / 14636778.2019 .1677149}$

(Interview 6)

Some participants mentioned that, due to the above mentioned constrains, they have already turned away patients who had undertaken tests with low clinical utility and/or had received results that did not seem to have relevance for their health. Having to refuse consultations with some patients was reported to be a source of frustration and tension for some.

I think that's a fair decision. But it was very frustrating. It didn't feel good, I must say. But then on the other hand, what could we do with that information? [...] I don't know how long it would have taken to look into all the data. But then you also have to think "ok, should this be prioritized compared to something else which might be more prioritized within healthcare?", because of course we are always dealing with prioritizing different cases.

(Interview 9)

Besides their responsibilities towards patients, it was also stated that clinical geneticists should guide and advice other physicians and try to raise awareness on genetics so different types of physicians would become more familiar with the parts of genetics that are relevant to their practice.

I think what we're trying to achieve is rather than getting every clinician fully cognizant of all the ramifications of genetic testing we are trying 
Kalokairinou, L., Borry, P., Howard, H.C. (2019). Attitudes and experiences of European clinical geneticists towards direct-to-consumer genetic testing: a qualitative interview study. NEW GENETICS AND SOCIETY, 38 (4), 410-429. doi:

$\underline{10.1080 / 14636778.2019 .1677149}$

to get different groups of physicians to understand different things... So

I suppose us geneticists, what we're trying to do is identify within each subspecialty across medicine what bits of genetics our colleagues need to know and understand so that they make sure that the right patient gets off at the right test at the right time. We can't do all of this ourselves. It is not appropriate that we do all of this ourselves, but we need to always be able to guide and advise and steer and teach our colleagues so that they can do the relevant bits themselves, supported by us and knowing that they can contact us at any time if they have any questions.

(Interview 2)

\section{Discussion}

The respondents reported that having consultations with patients regarding DTC genetic test results is rather unusual. This is in line with a number of studies in the USA, Canada and Australasia, which indicated that healthcare professionals tend to have limited experience with patients who have undergone DTC genetic testing. More specifically, a study by Powell et al. (2012) conducted in North Carolina, USA, reported that only five out of 234 primary care physicians participating had discussed DTC genetic test results with a patient. Similarly, a study among American genetic counselors conducted by Hock et al. (2011) revealed that while the vast majority of participants (83\%) had two or fewer inquiries about DTC genetic testing, only $14 \%$ of the respondents had received requests for test interpretation or discussion of such test results. Infrequent experiences were also reported by primary care providers, in a more recent study conducted in Alberta and Ontario, Canada (Carroll et al. 2016) and by genetic 
Kalokairinou, L., Borry, P., Howard, H.C. (2019). Attitudes and experiences of European clinical geneticists towards direct-to-consumer genetic testing: a qualitative interview study. NEW GENETICS AND SOCIETY, 38 (4), 410-429. doi:

$\underline{10.1080 / 14636778.2019 .1677149}$

counsellors and clinical geneticists, Members of the Human Genetics Society of Australasia participating in an online survey conducted by Brett et al. (2012). Higher percentages of healthcare professionals having been contacted at least once by DTC genetic testing consumers were reported in a previous study performed by Howard and Borry (44\% of 121 clinical geneticists participating) (Heidi Carmen Howard and Borry 2013). Nevertheless, the frequency of such consultations reported for each clinical geneticist was rather low.

The interviewees offered a number of possible explanations regarding their limited experience with such patients. First of all, it was mentioned that this may be the result of a limited uptake of such tests in the general population. While currently a number of studies indicate variable interest of the general public in consumer genomics (Covolo et al., 2015; Goldsmith et al., 2012), the exact size of the DTC genetic testing both in Europe and globally is difficult to be precisely estimated. However, relevant research has indicated that the value of DTC genetic testing market is expected to significantly increase in the coming years. More specifically, while in 2015 the global market for DTC genetic testing was valued at 70.2 million USD in 2015, it is expected to reach 340 million USD by 2022 (Credence Research 2016). At the same time, 23andMe's biobank amounts to more than 2 million samples and is considered to be one of the largest repository of DNA samples in the world (Regalado 2016), indicating that the uptake of such tests is far from negligible.

Furthermore, consumers purchasing GT for informational/educational/recreational purposes are unlikely to be referred to clinical geneticists for further consultation, unless (as was the case with one of the participants) the test results end up conferring medically significant information. This is consistent with the results reported by a longitudinal study among DTC 
Kalokairinou, L., Borry, P., Howard, H.C. (2019). Attitudes and experiences of European clinical geneticists towards direct-to-consumer genetic testing: a qualitative interview study. NEW GENETICS AND SOCIETY, 38 (4), 410-429. doi:

$\underline{10.1080 / 14636778.2019 .1677149}$

consumers, according to which, while $63 \%$ of the 1026 respondents reported that they were planning to share their test results with a healthcare provider, a six-month follow up revealed that only $27 \%$ of them had actually done so (van der Wouden et al. 2016). According to the study, the most frequently cited reason for not eventually sharing such results was that they were not considered to be important enough (van der Wouden et al. 2016).

The adequacy and efficiency of the public healthcare system, as well as the fact that, within the clinical context, most medical GT are covered by health insurance, was cited by many as a disincentive for the purchase of DTC GT. As underlined by most of the respondents, the (European) public healthcare systems usually offer a wide range of GT that are covered by health insurance for people qualifying for specific types of genetic testing. In this setting, the tests offered, to eligible people (based on certain criteria such as their family history), are, according to many of the respondents, of high clinical validity and utility. In order, however, to ensure the high quality of the tests and eligibility standards, the public healthcare system can be more restrictive in the offer of tests and associated with long waiting lists, compared to the wide offer of tests by DTC genetic testing companies, which have positioned themselves as a more flexible alternative.

Nevertheless, a study among 1000 Australians indicated that the general public favors genetic testing through physicians rather than DTC GT companies, as they tend to trust such companies less when it comes to protecting the privacy of research results and providing medical advice (Critchley et al., 2015). In addition, results of previous research report that the potential users tend to prefer access to genetic testing through physicians or express willingness to share the test results with a healthcare professional upon being tested (S E Gollust et al. 2012; Kolor et 
Kalokairinou, L., Borry, P., Howard, H.C. (2019). Attitudes and experiences of European clinical geneticists towards direct-to-consumer genetic testing: a qualitative interview study. NEW GENETICS AND SOCIETY, 38 (4), 410-429. doi:

$\underline{10.1080 / 14636778.2019 .1677149}$

al. 2012; Goldsmith et al. 2012). Therefore, mistrust in the public healthcare system, while possible, has not been reported by other studies to date to be a widespread reason for people resorting to DTC genetic testing companies.

In general, participants felt confident and sufficiently prepared to interpret the test results provided by DTC companies and considered that healthcare professionals with a specialization in genetics (e.g. clinical geneticists and genetic counsellors) are better placed to provide such interpretation compared to their colleagues without such specialization. The latter assumption is supported by a number of previous studies indicating that primary care professionals tend to have limited knowledge regarding genetics and felt unprepared to answer questions regarding DTC genetic testing. For example, in a study among 382 primary care providers in North Carolina, USA, only $15 \%$ felt confident discussing DTC genetic testing with their patients (Powell et al. 2012). In the same vein, Carroll et al. reported that most of the primary care providers from two Canadian provinces participating in their study expressed an almost complete lack of knowledge regarding DTC GT and expressed uncertainty on when to refer a patient to a genetics specialist (Carroll et al. 2016). Nevertheless, counter to these studies, 58\% of the 502 primary care physicians throughout the USA participating in a study by Bernhard et al. (2013) expressed their confidence in their own ability to interpret DTC reports after being provided with a sample report by the researchers.

However, respondents' confidence on their ability to interpret DTC test results was not shared by genetics specialists participating in previous studies. More specifically, a study conducted in the Australasia in 2012 (Brett et al. 2012) reported that only 7\% of the genetic health professionals participating felt well placed to interpret and explain to patients DTC genetic 
Kalokairinou, L., Borry, P., Howard, H.C. (2019). Attitudes and experiences of European clinical geneticists towards direct-to-consumer genetic testing: a qualitative interview study. NEW GENETICS AND SOCIETY, 38 (4), 410-429. doi:

$\underline{10.1080 / 14636778.2019 .1677149}$

testing results. Moreover, inconsistent levels of knowledge on DTC genetic testing among genetic counsellors were reported by Hock et al. (2011). A possible explanation for this discrepancy could be that these studies have taken place some years ago, when DTC genetic testing was relatively new and genetics specialists were less familiar with interpreting such results.

Taking into account the professional background of the respondents, it is not surprising that they were almost unanimous in favoring strongly the involvement of healthcare professionals in the provision of health-related genetic testing. This result is in line with one European and one American study among healthcare professionals. More specifically, according to a study conducted by Howard and Borry (2013), the majority of the European clinical geneticists participating stated that they value face-to-face consultations with individuals having undergone genetic testing for severe or actionable health conditions, while telephone consultations was deemed to be appropriate only under specific circumstances (Howard and Borry 2013). Support for involvement of healthcare professionals was also reported among American genetic counsellors participating in the survey study by Hock et al. (2011), where $56 \%$ stated that DTC genetic testing may be acceptable if it is provided along with genetic counseling. In the same study, only $12 \%$ considered that adequate information can be transmitted through online material (Hock et al. 2011).

The recent trend of DTC genetic testing companies to include genetic counseling in their services either by employing clinicians or by being affiliated with ones, does not seem to alleviate concerns regarding provision of adequate and objective genetic counseling among respondents. The assumption of many of the interviewees that genetic counseling provided by 
Kalokairinou, L., Borry, P., Howard, H.C. (2019). Attitudes and experiences of European clinical geneticists towards direct-to-consumer genetic testing: a qualitative interview study. NEW GENETICS AND SOCIETY, 38 (4), 410-429. doi:

$\underline{10.1080 / 14636778.2019 .1677149}$

healthcare professionals affiliated to DTC genetic testing companies may not be impartial has been a concern frequently mentioned in the literature (Heidi Carmen Howard and Borry 2012) and is supported by an interview study among clinicians in partnership with such companies (McGowan et al., 2014). This study suggests that the genomic knowledge of the clinicians participating is limited to information provided by the companies, raising questions regarding the adequacy of their knowledge and their ability to give substantive and independent advice (McGowan et al. 2014).

When discussing the obligations of clinicians in this context, most respondents considered that they have an obligation to accept consultations with individuals having undergone such tests in order to guide them through the interpretation of test results and the implementation of lifestyle changes, if needed. Nevertheless, just less than half of the genetic counsellors participating in the study by Hock et al. (2011) agreed that they have such obligation.

A reason for healthcare professionals being unwilling to hold consultations with DTC genetic testing consumers was reported to be the additional cost imposed by such consultations on the public healthcare system. Currently, there is no concrete evidence that DTC genetic testing is causing significant downstream costs. Nevertheless, it can be deducted from the answers of many of the participants that demand for genetic consultation by DTC genetic testing consumers, even though relatively limited, is a concern for healthcare professionals, as it could place pressure on the public healthcare system. This is especially the case taking into account that, as reported, in many European countries geneticists are limited and have scarce time and resources at their disposal. This means that potential consultations for tests of limited clinical validity and utility can come at the expense of other patients. 
Kalokairinou, L., Borry, P., Howard, H.C. (2019). Attitudes and experiences of European clinical geneticists towards direct-to-consumer genetic testing: a qualitative interview study. NEW GENETICS AND SOCIETY, 38 (4), 410-429. doi:

$\underline{10.1080 / 14636778.2019 .1677149}$

In this regard, it is worth noting that establishing clinical validity for most SNP-based GT for susceptibility to common complex disorders, can be challenging, as the gene-disease association for such disorders is not well defined (Cornel, van El, and Borry 2014). Similarly, as also stressed by participants, the probabilistic nature of such tests makes their clinical utility doubtful. Especially with regard to clinical utility, the subjective component inherent to this term adds a further level of complexity in its evaluation. Clinical utility has been given various definitions. In a narrow sense, clinical utility has been interpreted as "the ability of a screening or diagnostic test to prevent or ameliorate adverse health outcomes such as mortality, morbidity, or disability through the adoption of efficacious treatments conditioned on test results" (Grosse and Khoury 2006). In a broader sense, clinical utility has been interpreted to include personal utility, a notion that goes beyond clinical benefits and also includes social and emotional effects (Bunnik, Janssens, and Schermer 2015; Turrini and Prainsack 2016). Stricter criteria of clinical utility in terms of medical benefits may be important in order to prioritize the offer of genetic testing in the healthcare context (Cornel et al. 2014; Foster et al. 2009). However, when these tests are covered privately, and in the absence of likely harms, a broader perception of clinical utility that also takes into account aspects of personal utility of the tests for consumers may be proportionate (Foster, Mulvihill, and Sharp 2009; H C Howard et al. 2013). In order to assess the utility of such tests there is a need for more systematic evidence regarding their risks and benefits.

Overall, guidelines regarding the prioritization of cases are important, in order to ensure that patients have access to genetic consultations when necessary and that resources are not wasted on consultations for inappropriate tests or tests with low clinical validity and utility. In this 
Kalokairinou, L., Borry, P., Howard, H.C. (2019). Attitudes and experiences of European clinical geneticists towards direct-to-consumer genetic testing: a qualitative interview study. NEW GENETICS AND SOCIETY, 38 (4), 410-429. doi:

$\underline{10.1080 / 14636778.2019 .1677149}$

regard, priority should be given to patients who have underwent tests with established clinical validity and utility and consultations regarding the results is likely to improve the healthcare management of the patient (Cornel et 2014).

\section{Conclusion}

This study provides insight in the experiences and attitudes of European clinical geneticists towards DTC genetic testing. Our results indicate that holding consultations with patients regarding DTC genetic testing is not a widespread practice in European clinics. This was attributed by many, among others, to the efficiency of the healthcare systems in the countries they practice and the largely recreational nature of these tests. In this regard, it was stressed by some that DTC genetic testing consumers are more likely to be curious about their DNA, while people with concrete health concerns and family history of a disease will most likely resort to the healthcare system. Most participants considered the majority of DTC GT currently available to be of low clinical validity and utility, although some acknowledged that the reports can be of good quality. Perhaps unsurprisingly, the vast majority of participants supported the necessity of medical supervision and genetic counseling in the context of genetic testing. Many felt that it was their duty to provide consultations with patients having undergone DTC genetic testing, but some were concerned about potential waste of time and resources.

Overall, the respondents tend to be skeptical about the added value of DTC genetic testing for patients, especially with regard to the perceived adequacy of their national healthcare systems. Despite the relatively low number of DTC genetic testing consumers who seem to currently be entering the healthcare system, participants were concerned about potential downstream costs. 
Kalokairinou, L., Borry, P., Howard, H.C. (2019). Attitudes and experiences of European clinical geneticists towards direct-to-consumer genetic testing: a qualitative interview study. NEW GENETICS AND SOCIETY, 38 (4), 410-429. doi:

$\underline{10.1080 / 14636778.2019 .1677149}$

In this regard, it was stressed by some that following a prioritization system, be based on clear guidelines that take into account the clinical utility of tests, deemed necessary.

\section{Appendix}

Table I: Summary of reported experiences and views of participants towards DTC genetic testing 
Kalokairinou, L., Borry, P., Howard, H.C. (2019). Attitudes and experiences of European clinical geneticists towards direct-to-consumer genetic testing: a qualitative interview study. NEW GENETICS AND SOCIETY, 38 (4), 410-429. doi:

$\underline{10.1080 / 14636778.2019 .1677149}$

\section{References}

Allyse, Megan A, David H Robinson, Matthew J Ferber, and Richard R Sharp. 2018. "Directto-Consumer Testing 2.0: Emerging Models of Direct-to-Consumer Genetic Testing." Mayo Clinic Proceedings 93 (1). Elsevier: 113-20. doi:10.1016/j.mayocp.2017.11.001.

Baptista, Natalie M., Kurt D. Christensen, Deanna Alexis Carere, Simon A. Broadley, J. Scott Roberts, Robert C. Green, and ; for the PGen Study Group. 2016. "Adopting Genetics: Motivations and Outcomes of Personal Genomic Testing in Adult Adoptees." Genetics in Medicine 18 (9). Springer Nature: 924-32. doi:10.1038/gim.2015.192.

Berg, Bruce L. 2007. Qualitative Research Methods for the Social Sciences. London: Pearson. https://www.pearson.com/us/higher-education/product/Berg-QualitativeResearch-Methods-for-the-Social-Sciences-7th-Edition/9780205628070.html.

Bernhardt, Barbara A, Cara Zayac, Erynn S Gordon, Lisa Wawak, Reed E Pyeritz, and Sarah E Gollust. 2013. "Incorporating Direct-to-Consumer Genmic Information into Patient Care: Attitudes and Experiences of Primary Care Physicians" 9 (7): 683-92. doi:10.2217/pme.12.80.Incorporating.

Bloss, Cinnamon S, Nathan E Wineinger, Burcu F Darst, Nicholas J Schork, and Eric J Topol. 2013. "Impact of Direct-to-Consumer Genomic Testing at Long Term FollowUp.” Journal of Medical Genetics 50 (6): 393-400. doi:10.1136/jmedgenet-2012101207.

Bollinger, Juli Murphy, Robert C Green, and David Kaufman. 2013. "Attitudes about Regulation among Direct-to-Consumer Genetic Testing Customers.” Genetic Testing and Molecular Biomarkers 17 (5): 424-28. doi:10.1089/gtmb.2012.0453.

Borry, Pascal, Martina C Cornel, and Heidi C Howard. 2010. "Where Are You Going, Where Have You Been: A Recent History of the Direct-to-Consumer Genetic Testing Market." Journal of Community Genetics 1 (3): 101-6. doi:10.1007/s12687-010-0023-z.

Braun, Virginia, and Victoria Clarke. 2006. "Using Thematic Analysis in Psychology." Qualitative Research in Psychology 3 (2): 77-101. doi:10.1191/1478088706qp063oa.

Brett, Gemma R, Sylvia a Metcalfe, David J Amor, and Jane L Halliday. 2012. “An Exploration of Genetic Health Professionals' Experience with Direct-to-Consumer Genetic Testing in Their Clinical Practice." European Journal of Human Genetics : EJHG 20 (8). Nature Publishing Group: 825-30. doi:10.1038/ejhg.2012.13.

Bunnik, Eline M, A Cecile J W Janssens, and Maartje H N Schermer. 2015. "Personal Utility in Genomic Testing: Is There Such a Thing?" Journal of Medical Ethics 41 (4). Institute of Medical Ethics: 322-26. doi:10.1136/medethics-2013-101887. 
Kalokairinou, L., Borry, P., Howard, H.C. (2019). Attitudes and experiences of European clinical geneticists towards direct-to-consumer genetic testing: a qualitative interview study. NEW GENETICS AND SOCIETY, 38 (4), 410-429. doi:

$\underline{10.1080 / 14636778.2019 .1677149}$

Carroll, June C., Tutsirai Makuwaza, Donna P. Manca, Nicolette Sopcak, Joanne A Permaul, Mary Ann O'Brien, Ruth Heisey, et al. 2016. "Primary Care Providers' Experiences with and Perceptions of Personalized Genomic Medicine." Canadian Family Physician 62: e626-35. http://www.cfp.ca/content/cfp/62/10/e626.full.pdf.

Cherkas, Lynn F, Juliette M Harris, Elana Levinson, Tim D Spector, and Barbara Prainsack. 2010. "A Survey of UK Public Interest in Internet-Based Personal Genome Testing." PloS One 5 (10): e13473. doi:10.1371/journal.pone.0013473.

Cornel, Martina C, Carla G van El, and Pascal Borry. 2012. "The Challenge of Implementing Genetic Tests with Clinical Utility While Avoiding Unsound Applications." Journal of Community Genetics, 1-6. doi:10.1007/s12687-012-0121-1.

2014. "The Challenge of Implementing Genetic Tests with Clinical Utility While Avoiding Unsound Applications.” Journal of Community Genetics 5 (1): 7-12. doi:10.1007/s12687-012-0121-1.

Covolo, Loredana, Sara Rubinelli, Elisabetta Ceretti, and Umberto Gelatti. 2015. "InternetBased Direct-to-Consumer Genetic Testing: A Systematic Review." Journal of Medical Internet Research 17 (12). JMIR Publications Inc.: e279. doi:10.2196/jmir.4378.

Credence Research. 2016. "Direct-to-Consumer Genetic Testing Market And Forrscasts To 2022." https://www.credenceresearch.com/report/direct-to-consumer-genetic-testingmarket.

Critchley, Christine, Dianne Nicol, Margaret Otlowski, and Don Chalmers. 2015. "Public Reaction to Direct-to-Consumer Online Genetic Tests: Comparing Attitudes, Trust and Intentions across Commercial and Conventional Providers." Public Understanding of Science 24 (6). SAGE PublicationsSage UK: London, England: 731-50. doi:10.1177/0963662513519937.

Finlay, Teresa. 2017. "Testing the NHS: The Tensions between Personalized and Collective Medicine Produced by Personal Genomics in the UK." New Genetics and Society 36 (3). Routledge: 227-49. doi:10.1080/14636778.2017.1351873.

Foster, Morris W, John J Mulvihill, and Richard R Sharp. 2009. "Evaluating the Utility of Personal Genomic Information.” Genetics in Medicine 11 (8): 570-74. doi:10.1097/GIM.0b013e3181a2743e.

Goldsmith, Lesley, Leigh Jackson, Anita O'Connor, and Heather Skirton. 2012. "Direct-toConsumer Genomic Testing: Systematic Review of the Literature on User Perspectives." European Journal of Human Genetics 20 (8): 811-16. doi:10.1038/ejhg.2012.18.

. 2013. "Direct-to-Consumer Genomic Testing from the Perspective of the Health Professional: A Systematic Review of the Literature." Journal of Community Genetics 4 (2): 169-80. doi:10.1007/s12687-012-0135-8.

Gollust, S E, E S Gordon, C Zayac, G Griffin, M F Christman, R E Pyeritz, L Wawak, and B a Bernhardt. 2012. "Motivations and Perceptions of Early Adopters of Personalized 
Kalokairinou, L., Borry, P., Howard, H.C. (2019). Attitudes and experiences of European clinical geneticists towards direct-to-consumer genetic testing: a qualitative interview study. NEW GENETICS AND SOCIETY, 38 (4), 410-429. doi:

$\underline{10.1080 / 14636778.2019 .1677149}$

Genomics: Perspectives from Research Participants." Public Health Genomics 15 (1): 22-30. doi:10.1159/000327296.

Gollust, Sarah E., Stacy W. Gray, Deanna Alexis Carere, Barbara A. Koening, Lisa Soleymani Lehmann, Amy L. McGuire, Richard R. Sharp, et al. 2017. "Consumer Perspectives on Access to Direct-to-Consumer Genetic Testing: Role of Demographic Factors and the Testing Experience." The Milbank Quarterly 95 (2): 291-318. doi:10.1111/1468-0009.12262.

Grosse, Scott D, and Muin J Khoury. 2006. "What Is the Clinical Utility of Genetic Testing?" Genetics in Medicine 8 (7): 448-50. doi:10.1097/01.gim.0000227935.26763.c6.

Hock, Kathryn T, Kurt D Christensen, Beverly M Yashar, J Scott Roberts, Sarah E Gollust, and Wendy R Uhlmann. 2011. "Direct-to-Consumer Genetic Testing: An Assessment of Genetic Counselors' Knowledge and Beliefs." Genetics in Medicine: Official Journal of the American College of Medical Genetics 13 (4): 325-32. doi:10.1097/GIM.0b013e3182011636.

Hogarth, Stuart, Gail Javitt, and David Melzer. 2008. "The Current Landscape for Direct-toConsumer Genetic Testing: Legal, Ethical, and Policy Issues.” Annual Review of Genomics and Human Genetics 9 (1). Annual Reviews : 161-82. doi:10.1146/annurev.genom.9.081307.164319.

Howard, H C, E Swinnen, K Douw, H Vondeling, J-J Cassiman, A Cambon-Thomsen, and P Borry. 2013. "The Ethical Introduction of Genome-Based Information and Technologies into Public Health.” Public Health Genomics 16: 100-109. https://www-kargercom.kuleuven.ezproxy.kuleuven.be/Article/Pdf/346474.

Howard, Heidi Carmen, and Pascal Borry. 2012. "Is There a Doctor in the House?: The Presence of Physicians in the Direct-to-Consumer Genetic Testing Context." Journal of Community Genetics 3 (2): 105-12. doi:10.1007/s12687-011-0062-0.

. 2013. "Survey of European Clinical Geneticists on Awareness, Experiences and Attitudes towards Direct-to-Consumer Genetic Testing." Genome Medicine 5 (5). BioMed Central Ltd: 45. doi:10.1186/gm449.

Kalokairinou, Louiza, Pascal Borry, and Heidi Carmen Howard. 2017. "Regulating the Advertising of Genetic Tests in Europe: A Balancing Act." Journal of Medical Genetics 54 (10). BMJ Publishing Group Ltd: 651-56. doi:10.1136/jmedgenet-2017-104531.

Kalokairinou, Louiza, Heidi C Howard, Pascal Borry, Louiza Kalokairinou, Heidi C Howard, and Pascal Borry. 2014. "Direct-to-Consumer Genetic Testing." In ELS. Chichester, UK: John Wiley \& Sons, Ltd. doi:10.1002/9780470015902.a0025181.

Kolor, Katherine, Debra Duquette, Amy Zlot, Joan Foland, Beth Anderson, Rebecca Giles, Jennifer Wrathall, and Muin J Khoury. 2012. "Public Awareness and Use of Direct-toConsumer Personal Genomic Tests from Four State Population-Based Surveys, and Implications for Clinical and Public Health Practice." Genetics in Medicine: Official Journal of the American College of Medical Genetics 14 (10): 860-67. 
Kalokairinou, L., Borry, P., Howard, H.C. (2019). Attitudes and experiences of European clinical geneticists towards direct-to-consumer genetic testing: a qualitative interview study. NEW GENETICS AND SOCIETY, 38 (4), 410-429. doi:

$\underline{10.1080 / 14636778.2019 .1677149}$

doi:10.1038/gim.2012.67.

Lee, Sandra Soo-Jin. 2013. "American DNA The Politics of Potentiality in a Genomic Age." Current Anthropology 54 (7). doi:10.1086/670970.

McGowan, Michelle L., Jennifer R. Fishman, Richard A. Settersten, Marcie A. Lambrix, and Eric T. Juengst. 2014. "Gatekeepers or Intermediaries? The Role of Clinicians in Commercial Genomic Testing." Edited by Vicki Marsh. PLoS ONE 9 (9). Public Library of Science: e108484. doi:10.1371/journal.pone.0108484.

Mcguire, Amy L, Christina M Diaz, and Susan G Hilsenbeck. 2009. "Social Networkers' Attitudes Toward Direct-to-Consumer Personal Genome Testing." American Journal of Bioethics 9: 3-10. doi:10.1080/15265160902928209.Social.

Merriam, Sharan B. 2009. Qualitative Research A Guide to Design and Implementation Revised and Expanded from Qualitative Research and Case Study Applications in Education. San Francisco: Jossey Bass. https://leseprobe.buch.de/imagesadb/f2/46/f2465cf6-b1d1-4d13-829d-e5c985f6ee5c.pdf.

Ostergren, Jenny E, Michele C Gornick, Deanna Alexis Carere, Sarah S Kalia, Wendy R Uhlmann, Mack T Ruffin, Joanna L Mountain, Robert C Green, J Scott Roberts, and PGen Study Group. 2015. "How Well Do Customers of Direct-to-Consumer Personal Genomic Testing Services Comprehend Genetic Test Results? Findings from the Impact of Personal Genomics Study." Public Health Genomics 18 (4). NIH Public Access: 21624. doi:10.1159/000431250.

Powell, Karen P, Whitney a Cogswell, Carol a Christianson, Gaurav Dave, Amit Verma, Sonja Eubanks, and Vincent C Henrich. 2012. "Primary Care Physicians' Awareness, Experience and Opinions of Direct-to-Consumer Genetic Testing." Journal of Genetic Counseling 21 (1): 113-26. doi:10.1007/s10897-011-9390-9.

Regalado, Antonio. 2016. “23andMe Sells Data for Drug Search.” MIT Technology Review. https://www.technologyreview.com/s/601506/23andme-sells-data-for-drug-search/.

Sleurs, Elke, Louiza Kalokairinou, Heidi C. Howard, and Pascal Borry. 2015. "Promotion and Sales of Self-Tests Online." In Routledge Handbook of Medical Law and Ethics, edited by Yann Joly and Bartha Maria Knoppers, 286-300. London and New York. https://books.google.be/books?id=0XiQBAAAQBAJ\&pg=PT301\&lpg=PT301\&dq=elk e+sleurs+louiza+kalokairinou\&source $=$ bl\&ots=wnSgsPnZbe\&sig=3SCYfJq4tQJ8CVc YNnzni6JyHFg\&hl=en\&sa=X\&ved=0ahUKEwitifvjrv7ZAhXD26QKHZaLBrwQ6AEI $\mathrm{LzAB} \# \mathrm{v}=$ onepage \&q=elke sleurs louiza kalo.

Tamir, Sivan. 2010. "Direct-to-Consumer Genetic Testing: Ethical-Legal Perspectives and Practical Considerations.” Medical Law Review 18 (2). Oxford Univ Press: 213-38.

Turrini, Mauro, and Barbara Prainsack. 2016. "Beyond Clinical Utility: The Multiple Values of DTC Genetics." Applied \& Translational Genomics 8 (March). Elsevier: 4-8. doi:10.1016/J.ATG.2016.01.008. 
Kalokairinou, L., Borry, P., Howard, H.C. (2019). Attitudes and experiences of European clinical geneticists towards direct-to-consumer genetic testing: a qualitative interview study. NEW GENETICS AND SOCIETY, 38 (4), 410-429. doi:

$\underline{10.1080 / 14636778.2019 .1677149}$

Urban, Alexander, and Mark Schweda. 2018. "Clinical and Personal Utility of Genomic High-Throughput Technologies: Perspectives of Medical Professionals and Affected Persons." New Genetics and Society 37 (2). Routledge: 153-73. doi:10.1080/14636778.2018.1469976.

Vayena, E, E Gourna, J Streuli, E Hafen, and B Prainsack. 2012. "Experiences of Early Users of Direct-to-Consumer Genomics in Switzerland: An Exploratory Study." Public Health Genomics 15 (6): 352-62. doi:10.1159/000343792.

Wouden, Cathelijne H. van der, Deanna Alexis Carere, Anke H. Maitland-van der Zee, Mack T. Ruffin, J. Scott Roberts, and Robert C. Green. 2016. "Consumer Perceptions of Interactions With Primary Care Providers After Direct-to-Consumer Personal Genomic Testing." Annals of Internal Medicine 164 (8): 513. doi:10.7326/M15-0995. 